\title{
"QUANDO VEM UMA MÃE CHEFE DE FAMÍLIA PARA A TERAPIA": A ÓTICA DE TERAPEUTAS DE FAMÍLIA SOBRE A MONOPARENTALIDADE FEMININA
}

"WHEN A BREADWINNER -MOTHER COMES TO THE THERAPY": FAMILY THERAPISTS' VIEW OF FEMALE-HEADED SINGLE PARENTING

"CUANDO UNA MADRE JEFA DE FAMILIA VIENE PARA LA TERAPIA": LA PERSPECTIVA DE LOS TERAPEUTAS DE FAMILIA ACERCA DE LA MONOPARENTALIDAD FEMENINA

\author{
Fabiana Verza* \\ Marlene Neves Strey ${ }^{* *}$
}

\begin{abstract}
RESUMO
Investigou-se a percepção de cinco terapeutas de família acerca da monoparentalidade feminina e o papel dos estudos de gênero em sua formação profissional. Para tanto, utilizou-se de entrevista individual semidirigida. A análise crítica de discurso com abordagem sistêmica foi empregada, enfatizando os micro e macroelementos presentes nos discursos. Os resultados indicaram uma defasagem de estudos de gênero na formação básica das profissionais, que foi em parte suprida pela formação em Terapia Familiar Sistêmica. Percepções contraditórias e complementares caracterizaram o processo de análise dos dados. Ao se referirem às mulheres chefes de família e às suas relações com o contexto socioambiental e familiar, as falas variaram entre vieses de patologia e de promoção de saúde. Tais variações foram divididas entre a visão clínica e psicossocial do fenômeno e exigiram um posicionamento crítico de análise dos dados.
\end{abstract}

Palavras-chave: Monoparentalidade feminina. Gênero. Terapia Familiar Sistêmica.

\begin{abstract}
We have investigated the perception of five family therapists about femaleheaded single parenting and the role of gender studies in their professional training. Both, an Individual semi-structured interview and the Critical Discourse Analysis together with a systemic approach emphasizing micro and macro elements present in the discourses were applied. The results indicated
\end{abstract}

\footnotetext{
Texto recebido em 10 de junho de 2016 e aprovado para publicação em 18 de novembro de 2016.

Doutoranda em Psicologia Social (PUCRS/CNPq) pela Pontifícia Universidade Católica do Rio Grande do Sul (PUCRS/ CNPq), mestra em Psicologia, psicóloga, terapeuta de família e casal. Endereço: Rua Dom Antônio Passagi, 1411/902 - Bairro Exposição, Caxias do Sul-RS, Brasil. CEP: 95084-230. Telefone: (54) 99980-0667. E-mail: fabianaverza@hotmail.com.

** Doutora em Psicologia Social, mestra em Psicologia, pesquisadora CNPq, professora no Programa de Pós-Graduação em Psicologia da PUCRS, coordenadora do Grupo de Pesquisa Relações de Gênero. Endereço: Rua Garibaldi, 1244/501 - Bom Fim, Porto Alegre-RS, Brasil. CEP: 90035-052. E-mail: streymn@pucrs.br.
} 
a lack of gender studies in the professionals' basic training, which was partly compensated by the training in Systemic Family Therapy. Contradictory and complementary views were parts of the process of data analysis. When referring to female breadwinner and their relationships with environmental and family context, the discourses ranged from pathology biases and health promotion. Such variations were divided between clinical and psychosocial view of the phenomenon and required a critical positioning towards the data analysis.

Keywords: Single-parent women. Gender. Systemic Family Therapy.

\section{RESUMEN}

Fue investigada la percepción de cinco terapeutas de familia acerca de la monoparentalidad femenina y el rol de los estudios de género en su formación profesional. Para tal fueron utilizadas entrevistas individuales semidirigidas. El análisis crítico del discurso siguiendo un enfoque sistémico fue utilizado, haciendo hincapié entre micro y macro elementos presentes en los discursos. Los resultados indicaron una insuficiencia de estudios de género en la formación básica de los profesionales, que fue compensada en parte por la formación en terapia familiar sistémica. Ideas contradictorias y complementarias caracterizan el proceso de análisis de datos. Cuando se hace referencia a mujeres jefas de familia y sus relaciones con el contexto ambiental y familiar, las intervenciones variaron entre sesgos de patología y promoción de la salud. Tales variaciones se dividieron entre el punto de vista clínico y psicosocial del fenómeno y exigieron un posicionamiento crítico del análisis de los datos.

Palabras clave: Monoparentalidad femenina. Género. Terapia Familiar Sistémica.

\section{INTRODUÇÃO}

Oolocar em foco diferentes funcionamentos familiares é tornar públicas as mudanças as quais as famílias estão vivenciando em cada período histórico. Desde a perspectiva ecológico-sistêmica (Bronfenbrenner, 2002), os impactos de tais modificaçôes interferem em todos os níveis do sistema relacional e contribuem para transformações significativas nas relações sociais intra e extrafamiliares.

A família monoparental é o retrato de uma forma de organização domiciliar no Brasil, uma vez que representa o segundo maior grupo familiar no país (Instituto Brasileiro de Geografia e Estatística [IBGE], 2012). Assim como se fala em "caráter polissêmico" (Macedo, 2008) do termo "família", uma vez 
que seu conceito já foi amplamente discutido (Dessen, 2010; Diniz \& Coelho, 2005; Strey, 2007), também se fala da "condição" monoparental (Woortmann \& Woortmann, 2004), já que tais modelos de famílias não representam um grupo homogêneo.

Importante destacar que a noção de família como sistema (Minuchin, 1990) e a ênfase da terapia familiar sistêmica no processo de interação familiar em detrimento do foco no conteúdo dos problemas trazidos pela família (Schwartz \& Nichols, 2007) foram as grandes contribuições da perspectiva sistêmica para o entendimento da dinâmica familiar. Como continuidade desse processo de evolução da terapia familiar, a família monoparental feminina foi beneficiada pela crítica feminista e, mais especificamente, pela terapia familiar feminista, que ampliou, para além do reconhecimento legal, o apoio a tais estruturas familiares.

A preocupação central da terapia familiar feminista foi a de romper com relações desiguais de poder-saber entre terapeutas e pacientes (Neves \& Nogueira, 2003). Intervenções terapêuticas ancoradas em pressupostos da terapia citada passaram a auxiliar mulheres a lidar com as mais distintas formas de discriminação e opressão, enfocando suas práticas na identificação de suas capacidades e competências (Narvaz \& Koller, 2007).

As terapias feministas não se tratam de uma técnica terapêutica e sim de um conjunto de ações e de intervenções críticas que articulam o papel do social nas relações interpessoais e auxiliam na construção de um processo terapêutico mais democrático. Logo, os princípios feministas podem ser utilizados em diferentes tipos de psicoterapia, transformando modelos de intervenção de diversas abordagens teóricas em procedimentos terapêuticos feministas (Neves \& Nogueira, 2003).

A monoparentalidade feminina é um fenômeno psicossocial complexo e multidimensional e está vinculada a uma série de atribuiçôes e valores sociais (Macedo, 2008; Verza, Sattler, \& Strey, 2015). Portanto as práticas terapêuticas com mulheres chefes de família devem levar em conta todos esses aspectos descritos. Terapeutas familiares não estão isentos, isentas de interferências de gênero, tampouco de interferências sociais e culturais, mesmo que representem um papel profissional quando estão no exercício de suas atividades. Assim, justifica-se a necessidade de investigar como a inter-relação entre os fatores macro e microambientais se expressa na relação entre terapeutas de família e mulheres chefes de família.

Os paradigmas críticos de análise propostos nos estudos de gênero possibilitam uma releitura dos aspectos relacionados ao universo temático das famílias. Scott (1995) agregou o aspecto relacional ao conceito de gênero com o objetivo de 
introduzir a noção de reciprocidade, na qual mulheres e homens não podem ser estudados de forma isolada ou dentro de uma lógica binária. Conforme destaca Pinelli (2004), é impossível dissociar a análise das relações de gênero e de família, uma vez que esses conceitos estão profundamente interligados e as mudanças em um deles reflete na modificação de outros conceitos, e ambos estão expostos à força das mudanças sociais.

Assim, ancorado nos pressupostos sistêmicos e nos estudos de gênero, este artigo tem por objetivo conhecer a ótica de terapeutas familiares, quais características definem as famílias monoparentais femininas, como tais sistemas familiares se organizam em termos de estrutura em um nível micro e macrossocial, e qual o papel da terapia familiar sistêmica nesse processo. Dessa forma, este estudo focalizou em experiências de terapeutas familiares no atendimento a mulheres chefes de família que buscam por terapia individual, enfatizando aspectos da formação profissional das terapeutas no que tange às questóes de gênero.

\section{MÉTODO}

Este estudo seguiu uma proposta metodológica de enfoque qualitativo e delineamento exploratório-descritivo. O desenho da investigação utilizou a análise crítica de discurso, seguindo uma abordagem sistêmica (Falmagne, 2004), salientando os micro e macroelementos presentes nos discursos das participantes (Dijk, 2010, Fairclough, 2001).

Foram entrevistadas cinco terapeutas de família (com idades entre 40 e 70 anos) com experiência de atendimento psicoterapêutico dentro da abordagem sistêmica (variando de 10 a mais de 40 anos de atuação profissional). As profissionais foram selecionadas por conveniência, e os critérios de participação foram: ter formação em terapia familiar sistêmica e trabalhar com Psicologia clínica. Uma vez explicados os objetivos do estudo, foi agendado um encontro com as terapeutas, que consentiram em participar mediante a assinatura do termo de consentimento livre e esclarecido.

O conteúdo das informações levantadas foi gravado em áudio e transcrito. Os dados foram coletados na entrevista individual, com roteiro semidirigido. Os tópicos abordados no roteiro foram definidos a priori e buscaram explorar questóes de gênero na formação profissional e na experiência clínica das entrevistadas, além de levantar as percepções das terapeutas acerca de agrupamentos familiares chefiados por mulheres. A posteriori, tais tópicos desmembraram-se em cinco eixos norteadores, os quais orientaram a análise dos macro e microelementos do discurso. 
Os macroelementos foram analisados com base no levantamento das impressões das participantes acerca da monoparentalidade feminina em um nível macrossocial. Foram considerados aspectos como o entendimento conceitual da monoparentalidade feminina, a exploração da dinâmica da estrutura familiar e as percepções sociais referentes a tais configurações familiares. Quanto à análise dos microelementos do discurso, o foco de atenção foi direcionado a aspectos microssociais da relação terapeuta-cliente no processo terapêutico, a fim de conhecer as estratégias de intervenção descritas nas entrevistas e as formas de comunicação estabelecidas entre terapeutas e mulheres chefes de famílias.

Este estudo foi aprovado pelo comitê de ética em pesquisa da PUCRS, segundo o registro CAAE: 43943314.9.0000.5336. A fim de preservar a privacidade das entrevistadas e não permitir que sejam identificadas, optou-se por apresentar as participantes mediante as siglas (T1, T2, T3, T4 e T5).

Cabe destacar que as questôes de gênero se sobrepõem entre os macro e microelementos de análise, uma vez que elas estão imbricadas no contexto psicossocial em todas as esferas ecossistêmicas (Bronfenbrenner, 2002). Logo, elas podem ser consideradas como um importante marcador para a análise do fenômeno da monoparentalidade, visto que estão inter-relacionadas com o discurso, com as práticas clínicas e com a formação profissional das terapeutas entrevistadas.

\section{RESULTADOS E DISCUSSÃO}

Ancorados nos pressupostos da abordagem sistêmica (Falmagne, 2004) e da análise dos macro e microelementos de discurso (Fairclough, 2001; Dijk, 2010), os resultados foram construídos com base num esquema conceitual, conforme a figura:

Figura 1 - Esquema conceitual

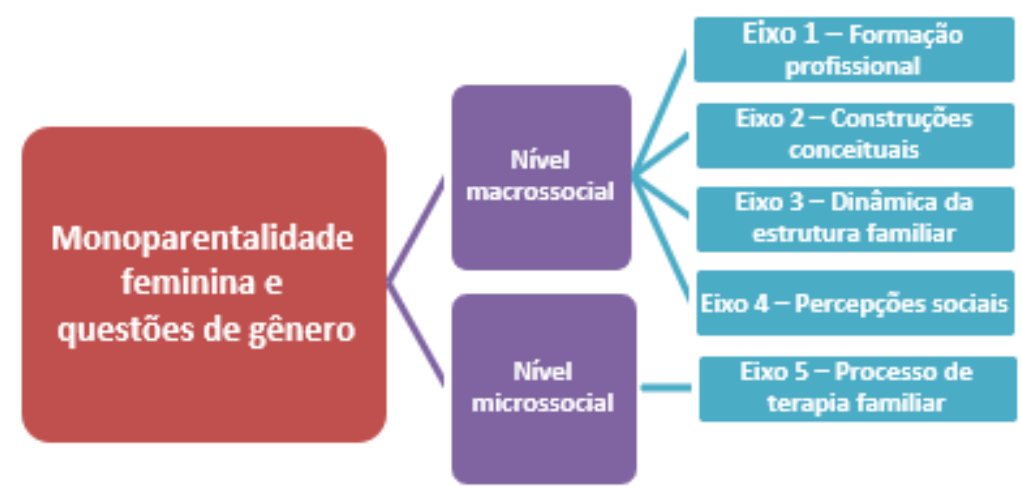

Fonte: elaborado pelas autoras. 
Tendo como guia norteador a "monoparentalidade feminina e questôes de gênero", chegou-se a dois níveis de análise (micro e macrossocial) e a cinco eixos temáticos compostos por itens da entrevista. Tais eixos foram subdivididos em categorias que orientaram para a análise dos macro e microelementos do discurso, presentes na fala das entrevistadas. Os quatro primeiros eixos abrangem resultados dos macroelementos de análise e estão divididos em eixo 1 - formação profissional; eixo 2 - construções conceituais; eixo 3 - dinâmica da estrutura familiar; eixo 4 - percepçóes sociais. Por fim, o eixo 5 - processo de terapia familiar, abrange resultados que compõem o nível microssocial de análise. Cabe salientar que os elementos de análise se sobrepóem em alguns aspectos, no entanto, para fins de compreensão conceitual do fenômeno, a construção de tal esquema foi fundamental.

Os macroelementos de análise foram analisados nos discursos de terapeutas familiares, com base no levantamento de suas impressões acerca da monoparentalidade feminina. O eixo 1 (formação profissional) descreve como os estudos de gênero foram inseridos na formação acadêmica das entrevistadas e impactaram a construção da identidade profissional destas. O eixo 2 (construções conceituais) analisa como se apresenta o entendimento das terapeutas acerca do conceito de monoparentalidade feminina. $\mathrm{O}$ eixo 3 (dinâmica da estrutura familiar) explora a percepção das terapeutas sobre o funcionamento dessas famílias e também descreve como as profissionais entendem que as mães monoparentais se percebem em sua tarefa parental. Por fim, o eixo 4 (percepçóes sociais) analisa a percepção das terapeutas sobre como a sociedade lida com agrupamentos familiares chefiados por mulheres. Os elementos do discurso analisados em cada eixo são derivados dos tópicos explorados no roteiro da entrevista. Embora tais elementos se inter-relacionem de forma dinâmica ao longo dos discursos, para uma melhor compreensão dos macroelementos de análise, os resultados foram divididos dentro do esquema apresentado na figura 2.

Figura 2 - Eixos temáticos 1, 2, 3 e 4 - Nível macrossocial

\begin{tabular}{l} 
Eixo 1: Formação \\
profissional \\
\hline -Mapeamento da \\
formaçãão profissional: \\
inclusẫo de estudos de \\
gênero. \\
\hline
\end{tabular}
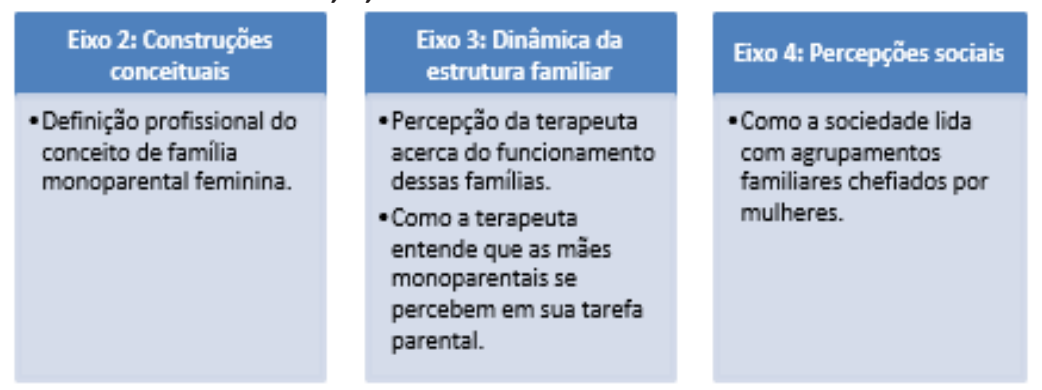

Fonte: elaborado pelas autoras.

Quanto à formação profissional (eixo 1), quatro participantes referiram não ter tido nenhum tipo de contato com a temática dos estudos de gênero durante a 
graduação: "Nunca! Inclusive a palavra gênero eu ouvi pela primeira vez no final dos anos 80!" (T4). A entrevistada mais jovem relatou um contato esporádico: "Teve nas disciplinas sociais. Não foi um grande foco" (T1).

Todas as entrevistadas relataram ter tido um contato mais aprofundado acerca dos estudos de gênero na formação em terapia de família: "Não foi nem em cursos de extensão. Eu tive isso na formação em terapia de família” (T3). Tais relatos apontam a defasagem curricular associada aos estudos de gênero na formação básica de Psicologia e revelam a importância da terapia familiar, mais especificamente da terapia familiar feminista, para a consolidação dos estudos de gênero nessa área do conhecimento. De acordo com Narvaz e Koller (2007), a terapia familiar feminista questionou a negligência de assuntos referentes a gênero na formação e na supervisão profissional e introduziu práticas terapêuticas focadas na realização de mudanças sociais, auxiliando as mulheres e suas famílias no combate às relações familiares ancoradas em estereótipos sexistas.

Ao analisar as construções conceituais (eixo 2) acerca do termo "família monoparental feminina”, os discursos circularam entre definições conceituais: "De uma maneira bem simples, é a família em que a mãe é responsável pela prole" (T5) e subjetivas: "Sobrecarga" (T2). A tentativa de definir conceitualmente tais unidades familiares tem uma função muito mais teórica do que prática. O conceito de família monoparental apresenta uma série de contradições, pois existem divergências no entendimento e na aplicação do referido conceito, além de uma vasta diversidade terminológica para nomear as ditas oposições (ou objeções) (Isotton \& Falke, 2014).

Quanto à dinâmica da estrutura familiar (eixo 3), os discursos das terapeutas acerca de suas percepçôes sobre o funcionamento das famílias monoparentais femininas revelaram uma visão clínica do fenômeno. Características de disfuncionalidade como vitimização, coleito, cobranças e aglutinação familiar predominaram nas falas das entrevistadas e levaram a desdobramentos de análise considerando aspectos como transgeracionalidade e relações de gênero.

A preocupação com grau de exigências no exercício da tarefa parental também é apontada como mais intensa em tais configurações familiares: "Meu filho tem que dar certo" (T2). Essas exigências estão relacionadas ao papel da mulher chefe de família, que é posto à prova nos âmbitos público e privado. Elas precisam dar conta das responsabilidades que lhes são impostas e provar à sociedade que são competentes em tal função (Verza, Sattler, \& Strey, 2015).

Quanto à opinião das terapeutas sobre como as mães monoparentais se percebem no exercício de suas tarefas parentais (eixo 3 - dinâmica da estrutura familiar), parte dos discursos se assemelharam às suas percepções como 
terapeutas, o que indica que os macroelementos do discurso circularam entre os diferentes eixos mapeados neste estudo. Predominaram apontamentos tais como sobrecarga, fragilidade, culpa, insegurança, vitimização e solidão.

Dois aspectos chamaram a atenção para a análise. $\mathrm{O}$ primeiro trata da autossuficiência: "Algumas mulheres se sentem vitoriosas, negando o feminino e o masculino, considerando os homens meros reprodutores, desnecessários" (T5). Nessa seara de estereótipos, encontram-se as "supermães", que dão conta de tudo sozinhas; as "mães matriarcas", que fazem com que todas as relações girem em torno de si; e as "mães de uma família incompleta", em que as causas de qualquer problema familiar ficam associadas a tal condição (Verza et al., 2015).

Diante disso, o segundo apontamento se refere ao sentimento de fragilidade e incompletude: "Elas passam a ter uma ideia mais presente da incompletude" (T1). "Culpadas, inseguras [... .] Querendo aprovação [. . . ' Meu filho está mal por minha causa [. . .]"” (T2). A monoparentalidade feminina em si não pode estar associada ao desenvolvimento de estruturas familiares problemáticas (Verza, 2016), no entanto parece ter um impacto significativo na ótica das terapeutas entrevistadas.

A aceitação da realidade também foi um apontamento importante: "Há aquelas mulheres que têm saídas mais equilibradas, que entendem que estão vivendo uma situação particular que é muito desafiadora" (T5). Novamente a questão de gênero foi levantada, trazendo à tona a discussão sobre a condição feminina e, mais especificamente, a condição da maternidade. "Mas, a culpa, eu acho que a gente tem ou em dupla, ou sozinha" (T4). Na ótica das terapeutas, a existência de um parceiro não parece fazer a diferença no que compete à expressão da culpa em mães.

Culpar a mãe é uma herança da teoria psicológica (Goodrich, Rampage, Ellman, \& Halstead, 1990) e atinge a prática clínica desde suas origens. $\mathrm{Na}$ década de 1980, em uma revisão de literatura sobre a temática, Caplan e HallMccorquodale (1985 apud Goodrich et al., 1990) registraram 72 doenças psicológicas atribuídas ao fracasso materno. Mesmo que a crítica feminista tenha reduzido o impacto de tais heranças na Psicologia, nunca será possível afirmar que tais pressupostos tenham se extinguido nas avaliações e intervenções terapêuticas. Por isso a importância do debate acerca dessa temática.

O último eixo dos macroelementos de análise, percepções sociais (eixo 4) analisou a opinião das terapeutas sobre como a sociedade lida com agrupamentos familiares chefiados por mulheres. Os discursos apontaram contextos favoráveis e desfavoráveis ao funcionamento de sistemas monoparentais femininos, todavia chama a atenção o predomínio dos aspectos desfavoráveis. Um deles está ligado 
à questão socioeconômica: "Eu acho que a camada que nós estamos falando faz diferença! Uma mãe sozinha e pobre, aí dá pena, tem que ajudar. Já no meio que a gente vive [. . .]" (T4). Os estudos voltados a apontar a vulnerabilidade social de famílias monoparentais de baixa renda (Carvalho \& Almeida, 2003; Macedo, 2008) têm ocupado um lugar de maior destaque científico nessa temática, o que não deixa de ser um aspecto positivo. No entanto pesquisas voltadas a famílias chefiadas por mulheres em outras camadas sociais também são importantes, uma vez que ampliam o conhecimento acerca dessas estruturas familiares em suas diferentes características e demandas.

Outro aspecto desfavorável está associado à cultura, e surgem novamente as questôes da culpa e do feminino: "Acho que a gente ainda tem um resquício Freudiano que a culpa é da mãe; monoparental fica mais forte ainda" (T2). Por outro lado, a sociedade é responsabilizada pela forma mítica como lida com a monoparentalidade: "Eu acho que a sociedade cria um mito em torno [. . . Essa mãe fica empoderada demais e se sentindo boa demais e conhecedora demais [. . .]" (T1). Tais aspectos contraditórios nos discursos das entrevistadas revelam a forma ambivalente em que tais sistemas familiares ficam expostos. Parece que o estigma de incompletude é percebido não apenas como algo negativo, mas também reativo, uma vez que são diferentes em suas expressões, porém derivados da mesma lógica: reagindo à "falta de [. . .]".

Ainda dentro do eixo 4 (percepções sociais), o levantamento dos aspectos positivos ou negativos relacionados a tais sistemas familiares introduziu novos elementos de análise em nível macrossocial e reforçou aspectos já apontados nos discursos anteriormente analisados. Apontamentos voltados às relações intrafamiliares e ambientais revelaram que os pontos positivos e negativos presentes nas análises circularam dentro de uma lógica micro e macrossistêmica, uma vez que tais instâncias se interconectam nas falas das entrevistadas.

Quanto aos aspectos positivos, a coesão familiar é citada como um elemento favorecedor da organização familiar: "Tem uma coesão maior porque é uma pessoa que centraliza tudo" (T1). O entendimento de que a configuração monoparental feminina pode ser vivenciada como uma alternativa viável (Walters, Carter, Papp, \& Silverstein, 1996) para um bom funcionamento familiar rompe com paradigmas da clássica família biparental como modelo ideal de família: "Nada justifica um casamento que está em ruínas" (T5). A valorização da mulher como um modelo positivo de ser humano também é outro elemento do discurso "O fortalecimento mesmo da pessoa, a resiliência que ela acaba tendo” (T3). Ao internalizar esse modelo positivo, tais mulheres adquirem maior habilidade para lidar com fatores de risco e para promover relações mais positivas no meio intra e extrafamiliar. 
Quanto aos aspectos negativos, os discursos concentraram-se em situaçôes de perdas e de dificuldades vinculadas ao contexto familiar e ao social. Destacam-se apontamentos sobre dificuldades financeiras e ausência de suporte conjugal: "O suporte conjugal é um contexto muito bom” (T5). Diversos estudos apontam sentimento de solidão, desamparo e insatisfação em muitas mães que não dividem a tarefa parental com outra pessoa (Féres-Carneiro, 2003; Grzybowski, 2002).

A discriminação também é citada: "Existe a discriminação no aspecto negativo" (T3). Expressões sociais que promovam a marginalidade das estruturas familiares monoparentais femininas, mesmo que de forma indireta, acabam passando uma ideia de que tais sistemas familiares são frágeis e propícios ao desenvolvimento de seres humanos problemáticos (Verza, 2016). Logo, preconceitos, reducionismos, psicopatologismos, entre outros vieses de cunho discriminatório, também se perpetuam conforme a sociedade se desenvolve.

Quanto à análise dos microelementos presentes no discurso das terapeutas, o foco voltou-se ao processo da terapia familiar. Foram exploradas as estratégias de intervenção terapêutica descritas nas entrevistas e as formas de comunicação estabelecidas nas relações entre terapeutas e mulheres chefes de família.

Figura 3 - Eixo temático 5 - Nível microssocial

\section{Eixo 5 - Processo de terapia familiar}

- Conhecer o que leva mulheres chefes de família a buscar atendimento.

- Conhecer de que forma a terapeuta auxilia no atendimento terapêutico.

\section{Fonte: elaborado pelas autoras.}

No eixo 5 (processo de terapia familiar), o motivo de busca por terapia nunca está relacionado diretamente ao fato de ser uma família monoparental feminina, o que explica a razão de buscarem por terapia individual. No entanto os discursos das terapeutas apontaram aspectos que podem estar relacionados a essa configuração. A questão de autoridade e limites na educação foi um ponto bastante explorado: "Em geral é o que aparece pra mim, problema com drogas [. . .] Na circunstância da mulher sozinha, é uma autoridade, alguém que ajude a segurar" (T4). As mudanças nos papéis femininos trouxeram como consequência negativa uma sobrecarga de trabalho e de funções (Diniz, 2004). A associação da questão de autoridade e limites na circunstância da "mulher sozinha" traz à tona a discussão dos papéis familiares e das habilidades parentais generificadas. A ideologia da "falta" parece andar muito próxima à ideologia da "culpa".

A solidão novamente foi apontada junto à busca de orientação sobre como conduzir questôes vitais: "Sentimentos de solidão, dificuldades de estabelecer os 
limites no próprio filho, em definir os seus direitos enquanto mulher, adulta, emancipada" (T5). A discriminação, já apontada no eixo 4 como um aspecto negativo, aparece no eixo 5 como motivo de busca por terapia em razão do sentimento de humilhação. Atitudes discriminatórias extrapolam as fronteiras familiares e podem ser observadas no trabalho: "Dificuldade com a chefia, normalmente com figuras masculinas e relações de poder, como ser ameaçada na base do assédio: se não fizeres isso, eu vou solicitar o teu deslocamento pra unidade tal" (T3). Tais ameaças, quando se é a única provedora na família, causam um impacto muito profundo no senso de autonomia e na autoestima das mulheres.

A escola também pode revelar atitudes discriminatórias quando não se adequa às singularidades de cada família: "As mães sendo chamadas porque não ia ter o pai na festa do Dia dos Pais. Para a criança, aquilo estava bem, para escola é que não estava. Então isso mexeu muito com a mulher, e aí a vinda em função disso" (T3). Em situações como essas, os padrões do patriarcado e a discriminação sexual interferem negativamente na constituição da subjetividade feminina (McGoldrick, 2003). Em razão disso, sentimentos de humilhação, de revolta ou de desamparo acabam ocasionando desconforto emocional e interferindo negativamente na autoestima das mães que conduzem sozinhas suas famílias.

Chama a atenção nos discursos das terapeutas o foco no hiperdimensionamento de sintomas ao descreverem as mães monoparentais que buscam atendimento psicoterápico. "Aí como eu te digo pela experiência clínica que eu tenho, alguns problemas que seriam questóes do ciclo de vida ou questôes de adolescência, para elas, têm uma dimensão muito maior" (T2). Essa vulnerabilidade emocional à qual algumas mulheres chefes de família ficam expostas somada aos diversos aspectos negativos e contextos desfavoráveis apontados neste estudo indicam a importância de investigar em profundidade os motivos de busca por terapia. Tais investigações contribuiriam para a elaboração de estratégias de intervenções terapêuticas, além de dimensionar o impacto social de aspectos como a cultura, o gênero, entre outros marcadores, sobre o funcionamento de cada família e de cada mulher envolvida em um processo terapêutico.

Dentro disso, foi elaborado o último item do eixo 4 (processo terapêutico), com o objetivo de conhecer como as terapeutas auxiliam as mulheres chefes de família que buscam por atendimento. Diversos foram os elementos de análise levantados, o que ampliou o conhecimento do processo terapêutico. As diferentes estratégias de intervenção descritas possibilitaram um entendimento maior de como se processa o auxílio terapêutico. Tais estratégias focaram-se no trabalho de investimento em recursos internos e na busca por auxílios externos. 
O mapeamento da realidade se apresentou como um ponto de partida inicial para a construção de um processo terapêutico:

A primeira coisa que eu tento fazer é um mapeamento da realidade daquela pessoa, com quem ela realmente pode contar e, na maioria das vezes, chega-se à conclusão de que não tem quase ninguém com quem contar, aí é a aceitação dessa realidade (T1).

Soma-se a essas estratégias o mapeamento da rede de apoio: "Aí eu procuro focar muito nas questôes de rede [. . .] Quem mais pode te ajudar" (T4). O investimento na rede de apoio social é uma constante nas intervenções clínicas e nas práticas sociais. Apontada como fundamental para a reestruturação intrapsíquica e relacional (Neves \& Nogueira, 2003), a rede social pessoal ou a rede social significativa conecta a perspectiva sistêmica utilizada pela terapia familiar às mudanças do ambiente ecológico (Sluzki, 1997). Logo, a busca por apoio é ampliada para além da família e inclui toda uma rede de relações diretas ou indiretas que o meio oferece.

Outro ponto importante é a exploração dos recursos pessoais: "Quais os recursos que eu tenho como mãe e como que eu vou distribuir esses recursos para dar conta do meu cotidiano" (T1). Dentro dessa lógica de auxílio terapêutico, a redefinição de tarefas também se apresentou como uma alternativa promotora de mudanças positivas: "Eu ensino elas a lidar com o que vier de fora como lucro... Elas mais se aliviam do que ficam com pena de si mesmas" (T1).

O foco nas competências individuais apresentou-se como uma intervenção terapêutica fundamental para a promoção de mudanças: "E tu, de alguma forma, oportunizar e acreditar que a pessoa tem recursos [.. . Estão ali querendo desenvolver os seus recursos e a sua capacidade de cuidar de si mesma" (T5). O trabalho de resgate da identidade também se revelou uma estratégia terapêutica utilizada com vistas ao investimento em recursos internos: "Tentar redescobrir um pouquinho aquela mulher ali, porque vem uma mãe para terapia" (T2).

As intervenções acima descritas demonstram o investimento terapêutico na busca de recursos próprios das mulheres para dar conta de suas demandas de vida. Tais posturas terapêuticas corroboram a função primordial das terapias feministas, que é trabalhar o empoderamento das mulheres.

Já o combate à despatologização da condição feminina e às ideias estereotipadas de doenças físicas e mentais associadas ao "sexo frágil” (Neves \& Nogueira, 2003), outro foco central das terapias feministas, não parece muito presente nos discursos analisados. O hiperdimensionamento de sintomas relatados é um exemplo disso. A noção de "causas" ou "consequências" sobre a produção de sintomas é uma herança muito recorrente na formação profissional da Psicologia. A abordagem 
sistêmica é um modelo de intervenção no qual o processo terapêutico se constrói a partir do entendimento do contexto em que o cliente ou a cliente está inserido, inserida, considerando os fatores biopsicossociais envolvidos nas relaçôes inter e intrapessoais. Por isso pode ser considerado como um modelo de intervenção terapêutica que favorece o trabalho de questóes de gênero, classe, etnia, entre outras variáveis associadas.

Com base no exposto, foi possível realizar uma articulação dinâmica dos diferentes aspectos que compõem a problemática de análise da monoparentalidade feminina e sua relação com as questôes de gênero e da terapia familiar. Investigar, sob as lentes de gênero, a construção de conceitos e o desenvolvimento de práticas terapêuticas em sistemas familiares chefiados por mulheres oferece a pesquisadoras e pesquisadores uma oportunidade de acessar os múltiplos níveis de análise que compõem o estudo das famílias em suas diversidades de estruturas e de configurações.

\section{CONSIDERAÇÕES FINAIS}

O debate em torno do tema da monoparentalidade feminina ampliou o escopo de entendimento desse fenômeno com base em diferentes perspectivas (micro e macrossocial) e favoreceu a análise de questôes fundamentais, relacionadas direta ou indiretamente à temática proposta. Conhecer, a partir da ótica de terapeutas familiares, aspectos conceituais, percepções ancoradas em questões de gênero e apontamentos clínicos acerca do trabalho com mulheres chefes de família trouxe grandes contribuições para o estudo das famílias monoparentais femininas e para a terapia familiar.

A pouca expressividade dos estudos de gênero na formação básica das profissionais entrevistadas chamou a atenção para uma revisão da atual estrutura curricular das faculdades de Psicologia. Isso porque a defasagem curricular na área de gênero representa um reflexo do período em que cada profissional realizou sua formação, da mesma forma que a especialização em terapia familiar sistêmica acabou se transformando em um recurso para suprir tal déficit teórico. Logo, investigações a fim de levantar o que mudou quanto à inserção de estudos de gênero (e se mudou) nos programas de ensino superior em Psicologia da atualidade contribuiriam para um mapeamento do panorama atual dos programas de ensino.

Os "filtros de gênero" e a perspectiva sistêmica permearam a análise de todos os eixos propostos nessa investigação, portanto a lógica relacional sustentou as bases epistemológicas deste estudo. Com base nessa proposta metodológica, foi 
possível elaborar um esquema conceitual complexo, dividido em eixos temáticos orientados pelos elementos de análise em nível micro e macrossocial. No entanto cabe destacar que tais elementos não se expressaram de forma excludente, pois os aspectos apontados nos discursos das participantes se inter-relacionaram ao longo de todo o processo de análise dos dados.

Exemplo disso são os aspectos convergentes que se repetiram nos discursos das terapeutas em momentos diferentes de exploração do roteiro das entrevistas. Características como a sobrecarga, por exemplo, foram citadas tanto para definição conceitual de monoparentalidade (eixo 2) quanto para a expressão de aspectos negativos (eixo 4) e de busca por terapia individual (eixo 5).

O mesmo ocorreu com aspectos como solidão, discriminação, dificuldades financeiras, investimento em recursos internos, aceitação da realidade e busca por rede de apoio. Tais convergências de resultados expressam justamente o que a monoparentalidade feminina pode ser ou pode não ser sob o ponto de vista singular das profissionais que responderam às entrevistas.

Ocupadas de um papel profissional e inseridas em um contexto de investigação científica em que o cenário estava composto por uma pesquisadora/terapeuta, as participantes certamente ofereceram o seu melhor para contribuir com o processo de pesquisa. No entanto esse contexto de investigação, necessário ao exercício da pesquisa científica, apresentou limitações intrínsecas a seu modelo de execução. Isso porque, ao serem convidadas a pensar como as mulheres chefes de família se percebem em sua tarefa parental e como a sociedade as percebe, muitas profissionais repetiram suas impressões como terapeutas. Assim, o exercício de ampliar o ponto de vista por diferentes perspectivas foi desafiador ao longo de todo o processo de investigação.

No entanto, embora os resultados desta pesquisa não possam ser generalizados e tampouco considerados como irrefutáveis, é possível afirmar que eles representam um discurso originário de um contexto profissional atravessado por questóes culturais, sociais, econômicas e, sem dúvida, atravessados por questōes de gênero. Tais aspectos interferiram na forma como as profissionais se posicionaram em seus discursos e em suas práticas terapêuticas. Em razão disso, foi possível observar nos discursos das participantes percepções contraditórias e complementares sobre os tópicos levantados. Ao se referirem às mulheres chefes de família e a suas relações com o contexto socioambiental e familiar, os discursos variaram entre vieses de patologização e de promoção de saúde. Essas variações foram divididas entre a visão clínica e psicossocial do fenômeno e exigiram um posicionamento crítico de análise dos dados. 
Cabe destacar, no entanto, que as impressōes e as expressões das participantes investigadas são subjetivas e sujeitas ao escrutínio de uma pesquisadora que também seleciona e analisa de acordo com os "filtros" que a representam. Essas são limitações importantes a qualquer pesquisa científica, mas, ao mesmo tempo em que colocam por terra a questão da neutralidade em pesquisa, ampliam as alternativas de entendimento e de análise de um determinado fenômeno.

Outro aspecto de extrema importância é o contexto maior no qual investigadores e investigadoras e investigados e investigadas estão inseridos. As interferências do ambiente sobre o processo de construção do conhecimento são inúmeras e fundamentais para a compreensão da complexidade que envolve qualquer proposta de pesquisa. Logo, a responsabilidade dos atores envolvidos nesse processo deve ser trabalhada e explorada em sua totalidade. $\mathrm{O}$ ato de analisar, categorizar, opinar, validar, generalizar também é um ato social. O lugar de onde partem tais expressões de valores também é um espaço onde se produzem conhecimentos e se criam estereótipos. "Falar" como pesquisadora e "falar" em nome de terapeutas de família não é uma tarefa simples e fácil de cumprir, e exige muita responsabilidade. No entanto o resultado dessa interlocução revela o quanto é possível aprender sobre uma determinada temática e o quanto as possibilidades de entendimento do fenômeno são ilimitadas.

Diante do exposto, pode-se concluir que o estudo de famílias monoparentais femininas é um campo em expansão e merece ser investigado com base em diferentes pressupostos teóricos, epistemológicos e metodológicos. No caso específico desta investigação, os objetivos do estudo foram plenamente alcançados e trouxeram grandes contribuições para o entendimento da monoparentalidade feminina. Por fim, os questionamentos que surgiram ao longo do processo de estudo podem ser transformados em novos desafios para o desenvolvimento de futuras pesquisas no campo da terapia familiar sistêmica e dos estudos de gênero. 


\section{REFERENCIAS}

Brofenbrenner, U. (2002). A ecologia do desenvolvimento humano: experimentos naturais e planejados. Porto Alegre: Artes Médicas.

Carvalho, I. M. M. D. \& Almeida, P. H. D. (2003). Família e proteção social. São Paulo em Perspectiva, 17(2), 109-122.

Dessen, M. A. (2010). Estudando a família em desenvolvimento: desafios conceituais e teóricos. Psicologia: Ciência e Profissão, 30(n. esp.), 202-219. Recuperadoapartirdehttp://dx.doi.org/10.1590/S1414-98932010000500010

Dijk, T. A. (2010). Análise crítica do discurso. In T. A. V. Dijk. Discurso e poder. (pp. 114-132). São Paulo: Contexto.

Diniz, G. R. S. (2004). Mulher, trabalho e saúde mental. In W. Codo (Org.), O trabalho enlouquece? Um encontro entre a clinica e o trabalho. (pp. 105-138). Petrópolis: Vozes.

Diniz, G. R. S. \& Coelho, V. L. D. (2005). A História e as histórias de mulheres sobre o casamento e a família. In T. Féres-Carneiro (Org.), Família e casal: efeitos da Contemporaneidade. (Vol. 1, pp. 138-157). Rio de Janeiro: EDPUC.

Fairclough, N. (2001). A prática da análise de discurso. In N. Fairclough. Discurso e mudança social. (2a ed.). (pp. 275-293). Brasília: Editora Universidade de Brasília.

Falmagne, R. J. (2004). On the constitution of "self" and "mind" the dialectic of the system and the person. Theory \& Psychology, 14(6), 822-845.

Féres-Carneiro, T. (2003). Construção e dissolução do laço conjugal na terapia de casal. In T. Féres-Carneiro (Org.), Família e casal: arranjos e demandas contemporâneas. (pp. 201-214). Rio de Janeiro: EDPUC.

Goodrich, J. T., Rampage, C., Ellman, B., \& Halstead, K. (1990). Terapia familiar feminista. Buenos Aires: Paidós.

Grzybowski, L. S. (2002). Famílias monoparentais: mulheres divorciadas chefes de família. In A. Wagner (Org.), Família em cena: tramas, dramas e transformaçôes. (pp. 39-53). Petrópolis: Vozes.

Instituto Brasileiro de Geografia e Estatística. (2012). Censo Demográfico 2010: familias e domicilios: resultados da amostra. (pp. 1-203). Rio de Janeiro: IBGE. Recuperado a partir de http://www.censo2010.ibge.gov.br. 
Isotton, R. \& Falcke, D. (2014). Quando um dos genitores detém a guarda dos filhos: que configuração familiar é essa? Pensando Famílias, 18(1), 92-106.

Macedo, M. S. (2008). Mulheres chefes de família e a perspectiva de gênero: trajetória de um tema e a crítica sobre a feminização da pobreza. Caderno CRH, 21(53), 389-404.

McGoldrick, M. (2003). Pertencimento e libertação: encontrando um lugar chamado "lar". In M. McGoldrick. Novas abordagens da terapia familiar: raça, cultura e gênero na prática clínica. (pp. 244-260). São Paulo: Roca.

Minuchin, S. (1990). Famílias: funcionamento \& tratamento. Porto Alegre: Artes Médicas.

Narvaz, M. G. \& Koller, S. H. (2007). A marginalização dos estudos feministas e de gênero na psicologia acadêmica contemporânea. Psico, 38(3), 216-223.

Neves, S., \& Nogueira, C. (2003). A psicologia feminista e a violência contra as mulheres na intimidade: a (re) construção dos espaços terapêuticos. Psicologia \& Sociedade, 15(2), 43-64.

Pinnelli, A. (2004). Gênero e família nos países desenvolvidos. (Vol. 2. pp. 5598). Campinas: Associação Brasileira de Estudos Populacionais - ABEP. Recuperado a partir de http://www.abep.org.br/publicacoes/index.php/series/ article/view/60/58

Schwartz, C. R., \& Nichols, M. P. (2007). Terapia familiar conceitos e métodos. (7a ed.). Porto Alegre: Artes Médicas.

Scott, J. (1995). Gênero, uma categoria útil de análise histórica. Educação e Realidade, 20, 71-99.

Sluzki, C. (1997). A rede social na prática sistêmica: alternativas terapêuticas. São Paulo: Casa do Psicólogo.

Strey, M. N. (2007). Gênero, família e sociedade. In M. Strey, J. A. Silva Neto, \& R. L. Horta (Orgs.), Família e gênero. (pp. 17-38). Porto Alegre: Edipucrs.

Verza, F. (2016). Acontece nas melhores famílias...: ensaio temático. In M. N. Strey, F. Verza \& P. F. Romari (Orgs.). Gênero, cultura e familia: perspectivas multidisciplinares. (Vol. 10, pp. 170-185). Porto Alegre: Edipucrs.

Verza, F., Sattler, M. K., \& Strey, M. N. (2015). Mãe, mulher e chefe de família: perspectivas de gênero na terapia familiar. Pensando Famílias, 19(1), 46-60. 
Walters, M., Carter, B., Papp, P., \& Silverstein, O. (1996). Hacia una perspectiva feminista en la terapia familiar. In M. Walters, B. Carter, P. Papp, \& O. Silverstein (Eds.), La red invisible: pautas vinculadas al género en las relaciones familiares. (pp. 29-46). Barcelona: Paidós.

Woortmann, K. \& Woortmann, E. (2004). Monoparentalidade e chefia feminina: conceitos, contextos e circunstâncias. Brasília: UNB, DAN. (Série Antropologia, 357). 